\title{
NOTES
}

\section{Synthesis and Characterization of Photoconductive Polymers II. Carrier Injection from Se in Blend Polymers and Copolymers of Carbazole Based Vinyl Ethers}

\author{
Shah A. HAQUE and Toshiyuki URYU* \\ Institute of Industrial Science, University of Tokyo, \\ Roppongi, Minato-ku, Tokyo 106, Japan
}

(Received August 7, 1987)

\begin{abstract}
KEY WORDS Poly[2-(9-carbazolyl)ethyl vinyl ether] / Poly[2-(9-carbazolyl)ethyl 1-propenyl ether] / Charge-Transport / Quantum Efficiency / Injection Efficiency / Mobility /
\end{abstract}

The photoelectronic properties of pure carbazole-polymers are insufficient due either to lack of light absorption in the visible spectrum region or low quantum efficiency for photocarrier generation. This problem can be avoided by applying a thin layer of amorphous selenium $^{1,2}$ over the polymer film. Free charge carriers are generated in the selenium layer on exposure to light and holes or electrons are subsequently injected into and transported by the organic photoconductor layer. The ability of selenium to inject carriers into the chargetransport layer is very high and under conditions the carrier injection efficiency equals the proper efficiency of charge generation.

A number of papers ${ }^{1-5}$ has appeared on carrier injection efficiency in polymers sensitized with a thin layer of selenium. Turner and $\mathrm{Pai}^{6}$ reported the hole-mobility of poly[2-(9carbazolyl)ethyl vinyl ether] and a few of its copolymers with $N$-substituted compounds measured by the xerographic method. But they fail to adequately report field dependence of carrier injection efficiency of both homo- and copolymers. Furthermore, there is no report on the injection efficiency of poly[2-(9-carbazolyl)ethyl 1-propenyl ether], a homologue of the above polymer, and their copolymers with vinyl ethers. All these deficiencies warrant further investigation of the electronic properties of homo- and copolymers. We present here the surface potential photodecay characteristics and a comparative study of the carrier injection efficiency of the films of these polymers, their blends and copolymers.

\section{EXPERIMENTAL}

The polymers were purified thoroughly by reprecipitating from methanol for 3-4 times. The films were prepared by coating the polymer $(5$ to $10 \mathrm{mg}$ ) solution in $0.2 \mathrm{ml}$ chlorobenzene or dichlorobenzene on aluminium substrates. They were dried for $5 \mathrm{~h}$ at $40^{\circ} \mathrm{C}$ and then kept under vacuum for $2 \mathrm{~h}$. The thickness of the films ( 5 or $10 \mu \mathrm{m}$ ) was determined by cross-section photomicrographs. A thin layer (less than $0.5 \mu \mathrm{m}$ ) of amorphous selenium was vacuum deposited on the free surface of the polymer.

The carrier injection efficiency was measured by the standard photoinduced discharge technique. ${ }^{7}$ The initial decay rate of surface charge density, $\mathrm{d} Q / \mathrm{d} t$, may be expressed as, 


$$
\frac{\mathrm{d} Q}{\mathrm{~d} t}=C\left(\frac{\mathrm{d} V}{\mathrm{~d} t}\right)=-\Phi \cdot I e
$$

where $C$ is the capacitance per unit area, $\mathrm{d} V / \mathrm{d} t$ the initial decay rate of surface potential, $\Phi$ the quantum efficiency, $e$ the electronic charge, and $I$ the light intensity in photons $/ \mathrm{cm}^{2} \mathrm{~s}^{-1}$. The quantum efficiency is thus given ${ }^{2}$ as,

$$
\Phi=-\frac{\varepsilon}{4 \pi L e I}\left(\frac{\mathrm{d} V}{\mathrm{~d} t}\right),
$$

where $\varepsilon$ is the dielectric constant, normally taken as 3.0 for carbazole-polymers, and $L$, thickness of the film. For low intensity radiation $\Phi$ equals photoinjection efficiency. ${ }^{1}$

The selenium layer was charged by a voltage supplier (Glassman High Voltage Co.) to an initial positive potential $V_{\mathrm{o}}$, measured by an isoprobe (Monroe Electronics Inc., Model 244). The film was then exposed to low intensity (through TND filter, Toshiba) monochromatic radiation $(435 \mathrm{~nm})$ from Xe-lamp. The surface potential decay was recorded in an oscilloscope (Model, VP-5730A, National) and its rate of change at $V_{\mathrm{o}}$ was analyzed by NEC PC-8801 MKII and PC-9801VM

\begin{tabular}{|c|c|c|c|c|}
\hline \multirow{2}{*}{$\begin{array}{c}\text { Polymer } \\
\text { No. }\end{array}$} & \multirow[t]{2}{*}{ Sample ${ }^{b}$} & \multirow{2}{*}{$\begin{array}{l}\text { Polymer- } \\
\text { ization } \\
\text { condition }^{\mathrm{c}}\end{array}$} & $\begin{array}{l}\text { Content of } \\
\text { carbazole }\end{array}$ & \multirow{2}{*}{$\begin{array}{c}\bar{M}_{n} \\
\times 10^{-3}\end{array}$} \\
\hline & & & $\mathrm{wt} \%$ & \\
\hline \multirow[t]{2}{*}{1} & Poly-1 & A & - & 12.4 \\
\hline & Poly-2 ${ }^{\mathrm{d}}$ & A & & \\
\hline 2 & Poly-2S & & 70.0 & 2.3 \\
\hline 3 & Poly-2I & & 70.0 & 8.6 \\
\hline 4 & Poly-2' & B & 70.0 & 4.1 \\
\hline 5 & Poly-3 & B & 66.1 & 5.1 \\
\hline 6 & Poly (1-co-3) & $\mathrm{C}$ & 34.3 & 55.0 \\
\hline 7 & Poly(1-co-3) & B & 46.8 & 28.2 \\
\hline
\end{tabular}

Table I. Homo- and copolymers of vinyl ethers ${ }^{\mathrm{a}}$

a For details of the polymerization, see ref 8 .

b 1, Ethyl vinyl ether; 2, 2-(9-carbazolyl)ethyl vinyl ether; 3, 2-(9-carbazolyl)ethyl 1-propenyl ether.

c $\mathrm{A}, \mathrm{CH}_{2} \mathrm{Cl}_{2} / \mathrm{BF}_{3} \mathrm{OEt}_{2}$ system; $\mathrm{B}$, toluene/ $/ \mathrm{AlEtCl}_{2}$ system; $\mathrm{C}$, toluene $/ \mathrm{BF}_{3} \mathrm{OEt}_{2}$ system.

d Partially insoluble in benzene; benzene soluble fraction (poly-2S) and benzene insoluble fraction (poly-2I). microcomputers.

\section{RESULTS AND DISCUSSION}

Table I shows the homo- and copolymers prepared in different solvent and catalyst systems. The details of the polymerizations and general characteristics of the polymers are discussed in our earlier communication. ${ }^{8}$ Poly(ethyl vinyl ether) (poly-1) is not a photoconductive polymer. It was used as an inert binder for the other two polymers. The molecular weights of the homopolymers were very
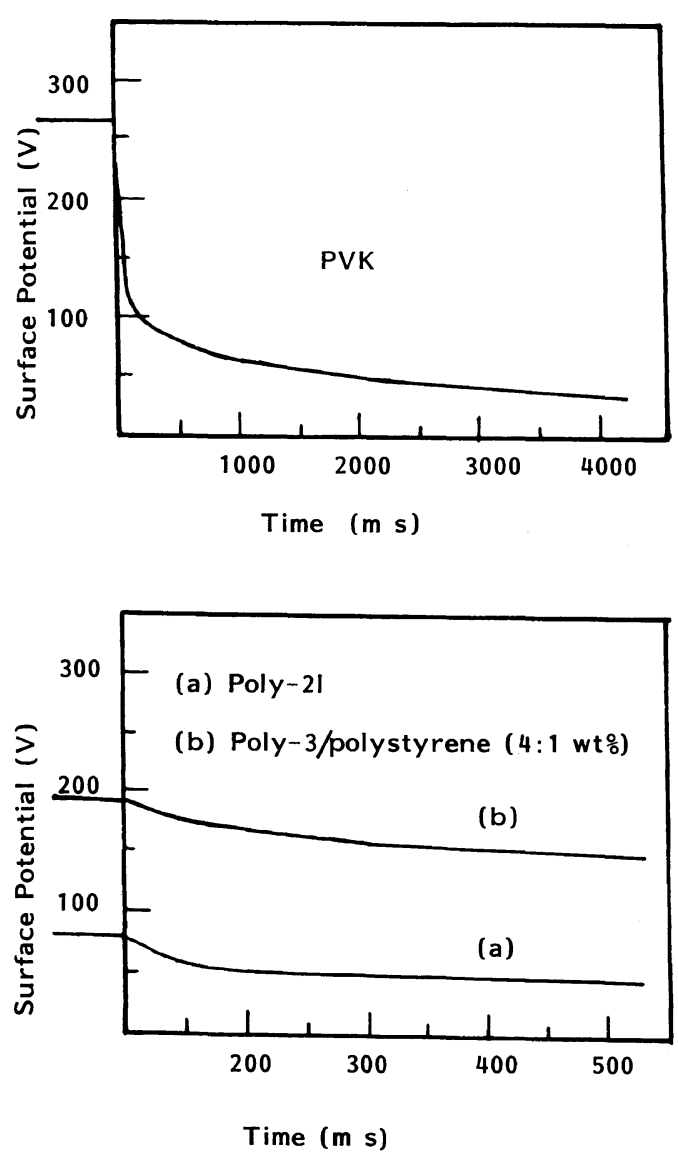

Figure 1. Typical time-resolved photoinduced discharge curves with $435 \mathrm{~nm}$ radiation for all samples. The light intensity for PVK-Se $(5 \mu \mathrm{m})$ film is $2.19 \times 10^{14}$ photons $/ \mathrm{cm}^{2} \mathrm{~s}^{-1}$, and that for $10 \mu \mathrm{m}$ films of poly-2I (No. 3) and poly-3 (No. 5)/polystyrene is $2.85 \times 10^{14}$ photons $/ \mathrm{cm}^{2} \mathrm{~s}^{-1}$. 
low compared to the copolymers. The high molecular weight copolymers had good film forming properties compared to the low molecular weight homopolymers. The films of poly-2S and poly-2' could not be prepared, except for blending, because of their very low molecular weights.

Figure 1 shows typical time-resolved photoinduced discharge curves of the films of PVK, poly-2I (No. 3) and poly-3 (No. 5)/polystyrene blend $\left(4: 1 \mathrm{wt}^{\mathrm{o}} \%\right)$. The rate of discharge for standard PVK film is very high $\left((\mathrm{d} v / \mathrm{d} t)_{t=0}=\right.$ $-1.39 \times 10^{3} \mathrm{~V} \mathrm{~s}^{-1}$, at $\left.5.3 \times 10^{5} \mathrm{~V} \mathrm{~cm}^{-1}\right)$ as compared to the prepared poly-2I $\left((\mathrm{d} v / \mathrm{d} t)_{t=0}\right.$
$=-1.89 \times 10^{2} \mathrm{~V} \mathrm{~s}^{-1}$, at $\left.7.8 \times 10^{4} \mathrm{~V} \mathrm{~cm}^{-1}\right)$ and poly-3/polystyrene blend polymer $\left((\mathrm{d} v / \mathrm{d} t)_{t=0}\right.$ $=-1.73 \times 10^{2} \mathrm{~V} \mathrm{~s}^{-1}$, at $2.0 \times 10^{5} \mathrm{~V} \mathrm{~cm}^{-1}$. A higher initial field could not be achieved for pure poly-2I film (Figure 1a) because it cracked easily in high fields. In very low fields, the measurements became insignificant and inconsistent due to surface recombination or trapping of the charge carrier. ${ }^{2}$ It seems that sufficient recombination of the charge occurs at the interface between Se and poly2I which otherwise could show a sharp decrease and low residual potential. Aside from surface recombination, high residual

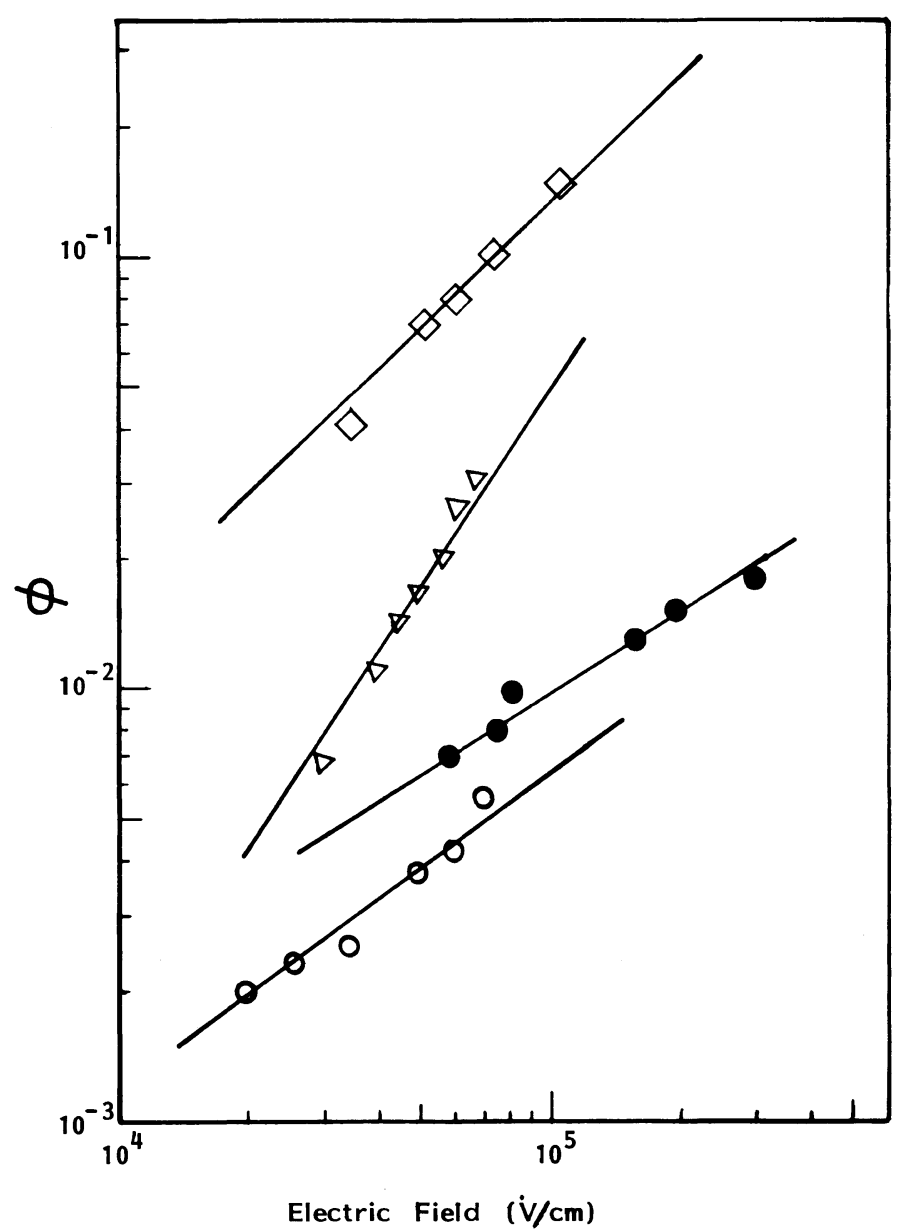

Figure 2. Apparent carrier injection efficiency of the films of $(\square)$ poly-3 $(\triangle)$ poly-2I polystyrene $(4: 1 \mathrm{wt} \%)$ and $(O)$ poly-2S/poly-1 $(4: 1 \mathrm{wt} \%)$. 
potential may result from the high level of bulk trapping. ${ }^{6}$ Such a case occurs in poly-3/ polystyrene blend film. The initial applied field is quite high but the potential does not decrease sharply. The reason for bulk impurity may be the binder unit in the polymer matrix. However, the possibility of crosslinking at the 3-3' position of the carbazole in both samples (Figure 1a and b) cannot be ruled out completely, and may cause bulk trapping and enhance residual potential.

Figure 2 shows the field dependence of the carrier injection efficiency of homopolymers and blend polymers. For all the polymers, the injection efficiency increased with the applied field, indicating that at relatively high field recombination of photogenerated charges becomes less significant. ${ }^{2}$ The injection efficiency is higher for homopolymers than that of the blend polymers. The apparent injection efficiency depends on mobility of the charge which in turn occurs through carbazole chromophore groups. As the concentration of carbazole groups decreases in blend polymer films, the injection efficiency also decreases. A comparison of injection efficiency of the blended films shows that the efficiency is higher for the polystyrene blend than the poly- 1 blend film. The polarity of the binder may impart a localized field on the photogenerated charges, retarding the mobility and hence the injection efficiency. Poly-1 is much more polar than polystyrene which seems to cause lower injection efficiency. The concentration of carbazole is higher in poly-2I than poly-3 but the injection efficiency is lower. The exact reason is not clear at the moment, but it is likely that the extra $\mathrm{CH}_{3}$ group in $\beta$-position of 3, [2-(9carbazolyl)ethyl 1-propenyl ether], plays some role in this effect.

Figure 3 shows the effect of inert binder in the carrier injection efficiency of poly-3 and poly-2' $2^{\prime}$. An efficiency of $10^{-1}$ was obtained for poly-3 at a field of $7 \times 10^{4} \mathrm{~V} \mathrm{~cm}^{-1}$ (Figure 2) whereas the same for the blend polymer was at a field of $1.5 \times 10^{6} \mathrm{~V} \mathrm{~cm}^{-1}$. This indicates that

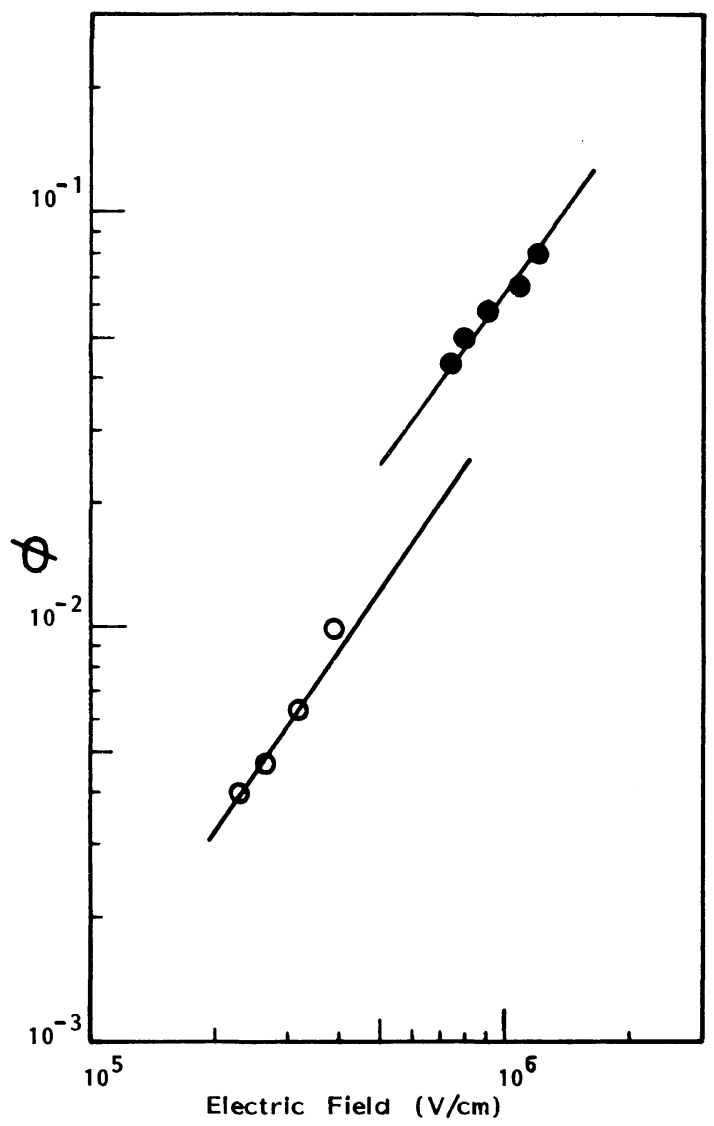

Figure 3. Apparent carrier injection efficiency of blended films of (O) poly-3/polystyrene $(4: 1 \mathrm{wt} \%)$ and $(O)$ poly-2, /polystyrene $(4: 1 \mathrm{wt} \%)$.

blended polymers need higher applied fields for an efficiency obtainable at lower fields for a homopolymer. However, the use of an inert binder is strongly justified in terms of stability of the film. Both the films of poly-2I and poly3 (Figure 2) crack in an applied field of $10^{5}$ $\mathrm{V} \mathrm{cm}^{-1}$ but the blended films of poly- 3 and poly-2 $2^{\prime}$ can withstand an electric field of $10^{6}$ $\mathrm{V} \mathrm{cm}^{-1}$.

Figure 4 shows the field dependence of the injection efficiency of two kinds of poly(1-co-3) of different carbazole content. At an applied electric field of $3 \times 10^{5} \mathrm{~V} \mathrm{~cm}^{-1}$, the quantum efficiencies are $2 \times 10^{-3}$ and $2 \times 10^{-2}$, respectively. The former copolymer (No. 6) contains $34.3 \mathrm{wt}^{\%} \%$ and the later copolymer (No. 7) 


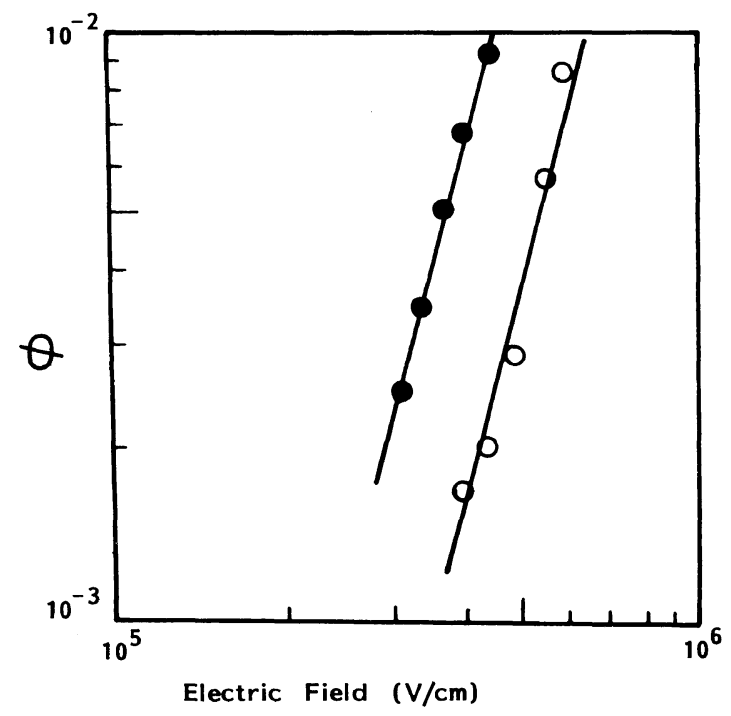

Figure 4. Apparent carrier injection efficiency of the films of poly(1-co-3), (O) No. 6 and (O) No. 7.

contains $46.9 \mathrm{wt} \%$ carbazole units. This clearly reconfirms on a quantitative basis that injection efficiency is dependent on the amount of carbazole units and it increases with the amount of carbazole in the polymer.

The above results may be summarized as (I) blending a low molecular weight polymer increases stability of the film in a higher electric field, (II) binder of less polarity is preferable as far as the injection efficiency is concerned, (III) efficiency increases with content of carbazole chromophore group whether it is a blend polymer or copolymer. The latter is better for getting high molecular weight which is a good film forming property.

Acknowledgements. The authors are indebted to Dr. R. Oshima for critically reading the manuscript. SAH thanks the Ministry of Education, Japan for financial assistance.

\section{REFERENCES}

1. W. Mey, P. M. Borsenberger, and A. Chowdry, J. Appl. Phys., 49, 3607 (1978).

2. P. M. Borsenberger and A. I. Ateya, J. Appl. Phys., 49, 4035 (1978).

3. P. M. Borsenberger, L. E. Contois, and D. C. Hoesterey, J. Chem. Phys., 68, 637 (1978).

4. M. Ikeda, H. Sato, K. Morimoto, and Y. Murakami, Soc. Photogr. Scient. Engg., 19, 60 (1975).

5. K. Morimoto and Y. Murakami, Appl. Optics, Suppl., 3, 50 (1969).

6. S. R. Turner and D. M. Pai, Macromolecules, 12, 1 (1979).

7. J. Mort and I. Chen, "Applied Solid State Science," Academic, New York, N. Y., 1975, p 77.

8. S. A. Haque, T. Uryu, and H. Ohkawa, Makromol. Chem., 188, 2523 (1987). 